Document downloaded from:

http://hdl.handle.net/10251/51745

This paper must be cited as:

Presenda Barrera, A.; Salvador Moya, MD.; Peñaranda Foix, FL.; Catalá Civera, JM.; Borrell Tomás, MA. (2014). Mechanical characterization of conventional and non-conventional sintering methods of commercial and lab-synthesized Y-TZP zirconia for dental applications. Advances in Science and Technology. 87:151-156.

doi:10.4028/www.scientific.net/AST.87.151.

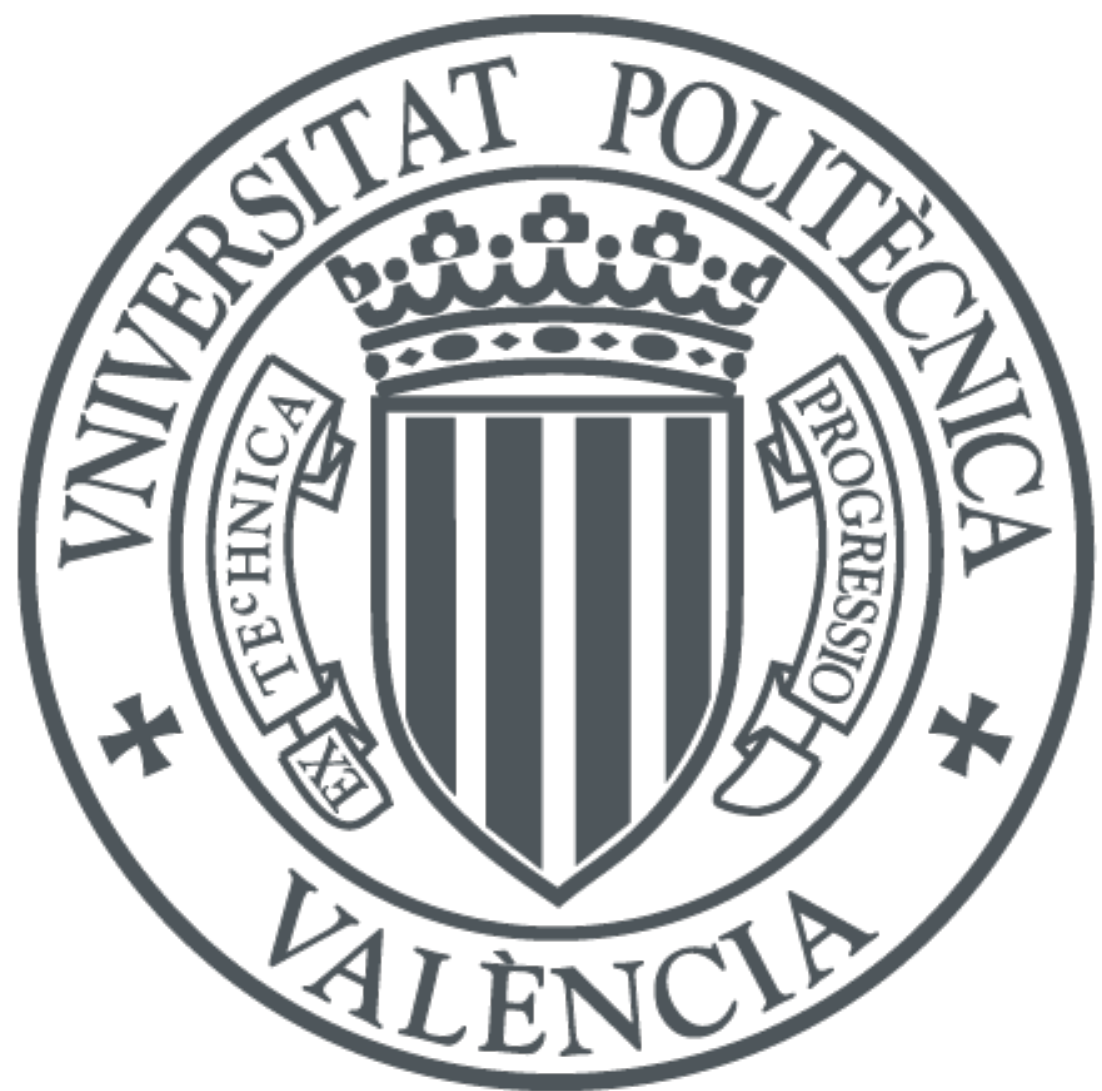

The final publication is available at

http://www.scientific.net/AST.87.151

Copyright Trans Tech Publications

Additional Information 


\title{
Mechanical Characterization of Conventional and Non-conventional Sintering Methods of Commercial and Lab-synthesized Y-TZP Zirconia for Dental Applications
}

\author{
Álvaro Presenda ${ }^{1, a^{*}}$, María Dolores Salvador ${ }^{1, b}$, Felipe Peñaranda-Foix ${ }^{2, c}$, \\ José Manuel Catalá, ${ }^{2, \mathrm{~d}}$, Amparo Borrell ${ }^{1, \mathrm{e}}$ \\ ${ }^{1}$ Instituto de Tecnología de Materiales (ITM), Universidad Politécnica de Valencia, Camino de Vera \\ $\mathrm{s} / \mathrm{n}, 46022$, Valencia, Spain \\ ${ }^{2}$ Instituto de Aplicaciones de las Tecnologías de la Información y de las Comunicaciones \\ Avanzadas (ITACA), Universidad Politécnica de Valencia, Camino de Vera s/n, 46022, Valencia, \\ Spain \\ aalpreba2@upvnet.upv.es, bdsalva@mcm.upv.es, ${ }^{\mathrm{c} f p e n a r a n @ d c o m . u p v . e s, ~}$ \\ djmcatala@dcom.upv.es, eaborrell@upv.es
}

Keywords: Y-TZP zirconia; microwave sintering; mechanical properties; microstructure; dental applications

\begin{abstract}
Ceramics for dental applications have become increasingly important in the last decades. Particularly, the introduction of yttria-stabilized zirconia tetragonal polycrystalline (Y-TZP) materials as an alternative to the manufacturing of dental implants and prosthesis has provided a powerful tool to meet the demands required for these replacements in terms of biocompatibility, toughness, hardness and optical properties. Several commercial Y-TZP materials are currently available on the market and strong efforts in research and development facilities are being carried out to improve processing of Y-TZP to fully consolidate odontological pieces. Novel processing methods for ceramic powder sintering, including Y-TZP, aim to reduce processing times and production costs significantly, while maintaining or even improving the resulting microstructure and mechanical properties of the material. One of these methods includes microwave sintering. The purpose of this study is to characterize and compare the resulting properties of Y-TZP materials after conventional sintering and the non-conventional method of microwave heating. In this work one commercial material and one laboratory-synthesized Y-TZP powder are considered. The results suggest that microwave sintering results, generally, in better mechanical properties of the material in terms of hardness and fracture toughness than conventional sintering.
\end{abstract}

\section{Introduction}

Yttria-stabilized tetragonal zirconia polycrystalline (Y-TZP) materials have become increasingly important in the last few decades as biomaterials for dental replacements and implants. Due to their superior mechanical properties, null interaction with human tissue and enhanced optical properties, these materials have become widely applied commercially and its characteristics profoundly studied. Very fine-grain microstructures maybe obtained (size particle $<0.5 \mu \mathrm{m}$ ) with Y-TZP materials. Regarding mechanical properties, fracture toughness and hardness values are relatively high compared to other ceramic materials $\left(6-10 \mathrm{MPa} \cdot \mathrm{m}^{1 / 2}\right.$ and $1200 \mathrm{HV}$, respectively [1,9]) and fracture strength values oscillate between 900-1200 MPa, which allows them to satisfy the mechanical requirements in order to be considered for dental applications [2]. Y-TZP materials contain between 1.5-3.5 mol\%, since this range allows for almost $100 \%$ tetragonal $(t)$ phase content. The high fracture toughness values of Y-TZP ceramics are due to the strengthening that results when a phase transformation from $t$ to monoclinic $(m)$ zirconia occurs as a crack propagates through the material, in what is known as transformation toughening [3].

Mechanical properties are strongly influenced by the degree of densification of the ceramic powder. Solid-state sintering methods allow the consolidation of materials from compressed powders at high 
temperatures, below their melting point. Conventional sintering is based on conventional heat transfer mechanisms: conduction, convection and radiation. This method, however, has several limitations due to its long processing times that result in grain broadening and, as a consequence, a slight decrease in the mechanical properties of the material. It also requires a high energy consumption to reach and maintain such high temperatures for long periods of time (usually around $2 \mathrm{~h}$ ) if homogeneous materials are desired.

Currently, new methods for sintering ceramic powders are being explored and studied in order to obtain fully-consolidated materials through different mechanisms that may result in relative densities closer to theoretical values while maintaining fine-grain microstructures (Fig. 1). The main purpose for modifying sintering mechanisms is to obtain full densification of the material first followed by a controlled, but limited, grain growth. This can, in turn, improve the resulting mechanical properties of the ceramic material.

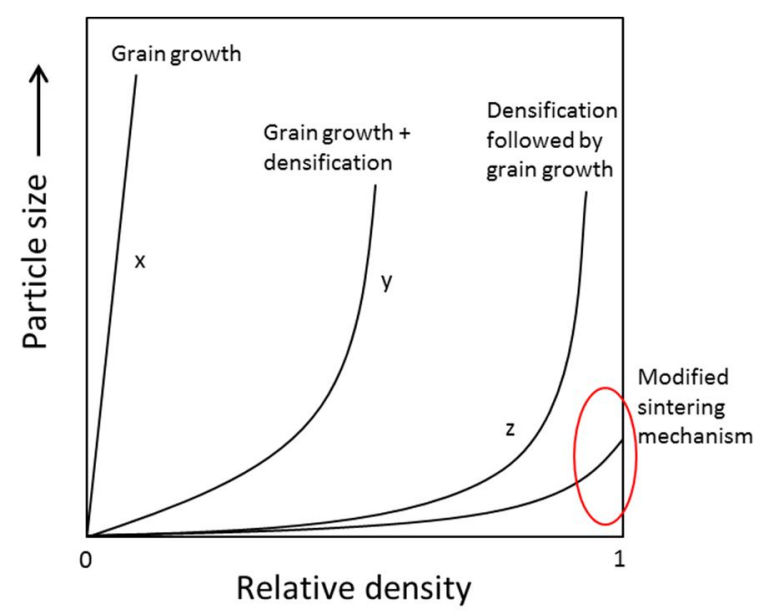

Figure 1. Densification curves for different cases due to solid-state sintering. $x$ : grain growth with very low densification; y: grain growth followed by densification; $z$ : densification followed by grain growth. M odified sintering mechanisms allow for high-degree densification first, followed by controlled and limited grain growth.

One novel method that allows for the modification of the densification mechanism of ceramic powders, including Y-TZP, is microwave sintering. With this method, highly dense materials can be obtained without substantial grain broadening because the processing times are considerably shorter than in conventional sintering, by almost a factor of 10 [4]. Energy consumption is also significantly reduced as a consequence of the mechanisms involve in microwave heating and the aforementioned shortening of processing times. As a result, several advantages arise including improved mechanical properties, reduced environmental impact, lower processing costs and faster heating rates $[5,10]$.

\section{Materials and Methods}

Two Y-TZP materials stabilized with 3 mol\% $\mathrm{Y}_{2} \mathrm{O}_{3}$ are considered and evaluated in this work: one commercial material readily available and widely utilized for dental and biomedical applications, referred to as COMMERCIAL in this study, and one lab-synthesized powder with a previous, controlled rheological study, referred to as LAB. The purpose for selecting these materials is to compare the resulting properties of a commercial one to those of a more adjusted and carefully prepared starting material.

COMMERCIAL material was provided by the manufacturer as a powder (nanometric particle size). Samples were obtained by uniaxial compression of the powder in order to consolidate "green", cylindrical bodies with a $10 \mathrm{~mm}$ diameter. LAB material was provided by a research institution as "green", cylindrical bodies. Sintering of samples by the conventional method was carried out in an 
electrical furnace (Thermolyne type 46100, Thermo Fisher Scientific) for $2 \mathrm{~h}$ in atmospheric conditions at two different temperatures: $1300{ }^{\circ} \mathrm{C}$ and $1400{ }^{\circ} \mathrm{C}$.

Microwave sintering of samples was performed in an experimental microwave system designed and developed by the ITACA-UPV. Samples were introduced in a rectangular cavity that is automatically adjusted to optimize microwave absorption by the material and control the heating rates $\left(100{ }^{\circ} \mathrm{C} / \mathrm{min}\right)$ and sintering temperature $\left(1200\right.$ and $\left.1300{ }^{\circ} \mathrm{C}\right)$. Sintering parameters were previously introduced in the control software $[7,8]$.

Densification of the sintered samples is evaluated in terms of relative density and has been determined by Archimedes method, following ASTM Standard C 373. Mechanical properties were evaluated via micro-indentation techniques. Vickers hardness, $H_{v}$, values were measured applying loads of $500 \mathrm{~g}$ for $10 \mathrm{~s}$ with a Shimadzu HMV-20 micro-indenter. $K_{I C}$ values were calculated by measuring the cracks induced by applying loads of $2 \mathrm{~kg}$ for $10 \mathrm{~s}$ with an image analysis program and utilizing the equation proposed by Niihara [6]. Microstructural analysis was carried out by thermally etching the samples at $100{ }^{\circ} \mathrm{C}$ below the sintering temperature. Once etched, samples were prepared for Field Emission-Scanning Electron Microscopy (FE-SEM, Gemini Ultra 55 model, Zeiss).

\section{Results and Discussion}

Densification. Relative density values for samples sintered via microwaves (MW) and conventional sintering (CS) for both materials are shown in Figure 2. Figure 2a presents the relative density values obtained for COMMERCIAL material. A value of $95.2 \%$ has been determined for the MW samples at $1200{ }^{\circ} \mathrm{C}$, which is relatively low for this type of material sintered under these conditions. It was expected that it would reach at least 97\% [7]. However, this relative density value is still slightly above that of the CS sample that was sintered at $1300{ }^{\circ} \mathrm{C}$. When both sintering techniques are compared at the same temperature $\left(1300{ }^{\circ} \mathrm{C}\right)$, densification in terms of relative density is improved for MW-sintered materials compared to CS samples. MW sintering at $1300{ }^{\circ} \mathrm{C}$ resulted in a relative density slightly above $98 \%$, while CS at $1400{ }^{\circ} \mathrm{C}$ reached $99.5 \%$. From this analysis, it can be established that a comparable degree of densification of $\mathrm{MW}$-sintered samples at sintering temperatures $100{ }^{\circ} \mathrm{C}$ below those of $\mathrm{CS}$ and in one-eighth of the processing time may be reached for this material.

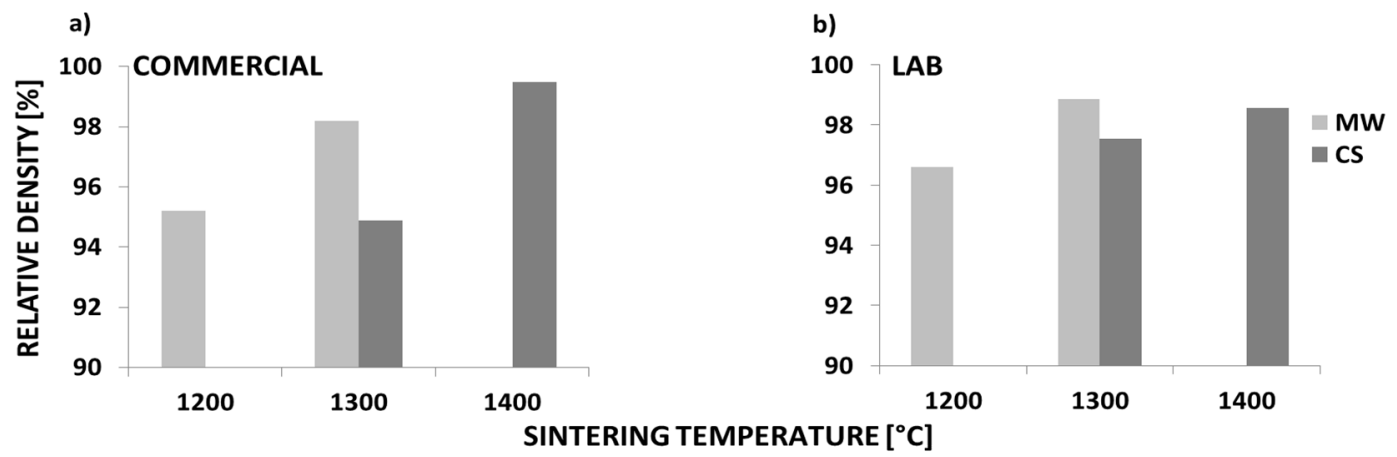

Figure 2. Resulting relative density values after microwave (M W) and conventional sintering (CS) at various temperatures. a) COM M ERCIAL Y-TZP and b) LAB Y-TZP.

LAB relative density values under both sintering conditions are shown in Figure $2 \mathrm{~b}$. Relative density is increased when sintering temperature in both MW and CS is increased. When comparing both sintering techniques at $1300{ }^{\circ} \mathrm{C}$, the $\mathrm{MW}$-sintered sample shows a higher relative density value, which is also higher than that of the CS sample that was sintered at a temperature of $1400{ }^{\circ} \mathrm{C}$. It is important to mention that for such a lab-synthesized material, MW sintering results in a higher densification of the "green" body. 
Mechanical properties. Regarding mechanical properties, $H_{v}$ and $K_{I C}$ values are presented in Figures 3 and 4, respectively, for both sintering methods. $H_{v}$ values for COMMERCIAL are summarized in Figure 3a. These values are generally high, ranging from 12.5 to $13.5 \mathrm{GPa}$. In this material, it is difficult to determine whether MW sintering results in higher $H_{v}$ with respect to CS since the values obtained at the same sintering temperature of $1300{ }^{\circ} \mathrm{C}$ are very similar and fall within the margin of error. However, it is possible to determine that MW sintering of this material at $1300{ }^{\circ} \mathrm{C}$ for 10 min results in $H_{v}$ values very close to those obtained for samples sintered by the conventional method at $1400{ }^{\circ} \mathrm{C}$ for $2 \mathrm{~h}$.

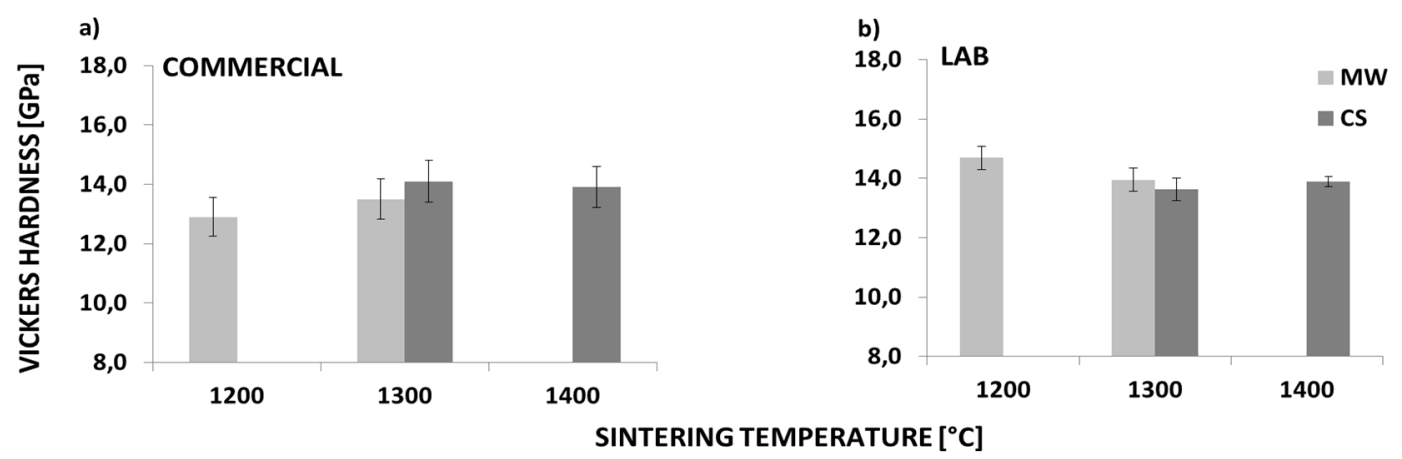

Figure 3. Resulting Vickers hardness values after microwave (MW) and conventional sintering (CS) at various temperatures. a) COM M ERCIAL Y-TZP and b) LAB Y-TZP.

In the case of LAB material, $H_{v}$ values are notably higher (all above $13.6 \mathrm{GPa}$ ) than those obtained for COMMERCIAL (Fig. 3b). This is due to the previous rheological study of the raw material that allows for the synthesis of a more homogenous powder and prevents the formation of aggregates. When comparing sintering methods, it is observed that MW-sintered samples result in higher $H_{v}$ values than CS. The highest $H_{v}$ value $(14.7 \mathrm{GPa})$ is obtained for MW sintering at $1200{ }^{\circ} \mathrm{C}$. This value is the highest for all materials and considering both sintering methods. $H_{v}$ is slightly decreased to $14.0 \mathrm{GPa}$ when increasing sintering temperature to $1300{ }^{\circ} \mathrm{C}$. These results indicate that microstructure of the samples needs to be analyzed to determine if there has been grain growth due to a higher sintering temperature and that the decrease in $H_{v}$ properties is due to the Hall-Petch effect. Both materials sintered by both methods have $H_{v}$ values above $12.0 \mathrm{GPa}$, a typical value for dental materials.

The $K_{I C}$ values for COMMERCIAL material (Fig. 4a) show important differences. MW-sintered samples have lower $K_{I C}$ values, around $4 \mathrm{MPa} \cdot \mathrm{m}^{1 / 2}$, than those sintered by the conventional method, which are above $5 \mathrm{MPa} \cdot \mathrm{m}^{1 / 2}$. A possible explanation for these values is that since this material was provided as a powder and "green" body samples were obtained by uniaxial compression, poor packing of the particles might have occurred leading to the formation of density gradients that are characteristic of uniaxial compression. In CS, processing time is increased substantially and this gives the particles more time to accommodate and consolidate, resulting in a more homogenously dense material, which is reflected in higher $K_{I C}$ values for these samples.

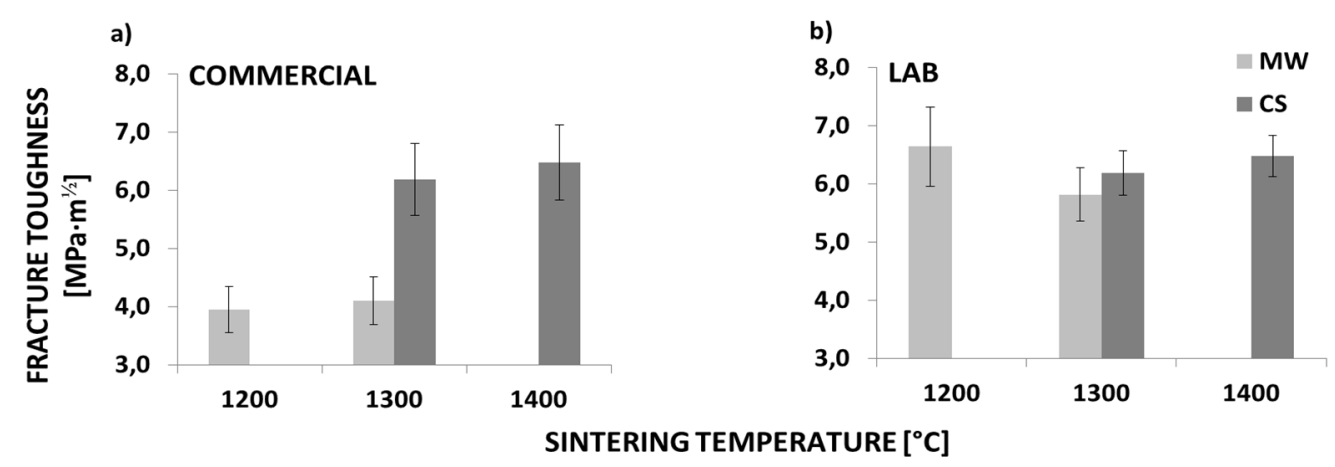

Figure 4. Resulting $K_{\mathrm{I}}$ values after microwave (MW) and conventional sintering (CS) at various temperatures. a) COM M ERCIAL Y-TZP and b) LAB Y-TZP. 
Results of the measured $K_{I C}$ values for LAB material are shown in Figure $5 \mathrm{c}$. As can be seen, these values oscillate between 5.8 and $6.7 \mathrm{MPa} \cdot \mathrm{m}^{1 / 2}$. MW sintering at $1200{ }^{\circ} \mathrm{C}$ for $10 \mathrm{~min}$ provides the highest $K_{I C}$ value at $6.64 \mathrm{MPa} \cdot \mathrm{m}^{1 / 2}$, even higher than $\mathrm{CS}$ at $1400{ }^{\circ} \mathrm{C}$ for $2 \mathrm{~h}$. When comparing both sintering techniques at the same temperature, $K_{I C}$ values are quite similar, with the $K_{I C}$ value of the CS sample slightly over that of the MW sample. For this material, fracture toughness is improved with MW sintering at $1200{ }^{\circ} \mathrm{C}$. Overall, all materials sintered and evaluated in this work have resulted in $K_{I C}$ values that fall within the range of values for materials applied in dentistry.

Microstructure and grain size. FE-SEM micrographs for both materials under specific sintering conditions are shown in Figure 5. In the micrographs for COMMERCIAL, an important variation in particle size can be observed. There is a significant variation in grain size for the $\mathrm{MW}$-sintered sample at $1300{ }^{\circ} \mathrm{C}$. Nonetheless, the average grain size of the MW-sintered samples (173 and 186 $\mathrm{nm}$ for 1200 and $1300{ }^{\circ} \mathrm{C}$, respectively) is still smaller than the average grain size for CS samples (229 and $286 \mathrm{~nm}$ for 1300 and $1400{ }^{\circ} \mathrm{C}$, respectively). This may be attributed to the heating rates, sintering time and heating mechanisms involved in MW sintering, which is a volumetric type of heating. The differences in grain size of Commercial B material samples between MW and CS are no more than $100 \mathrm{~nm}$.

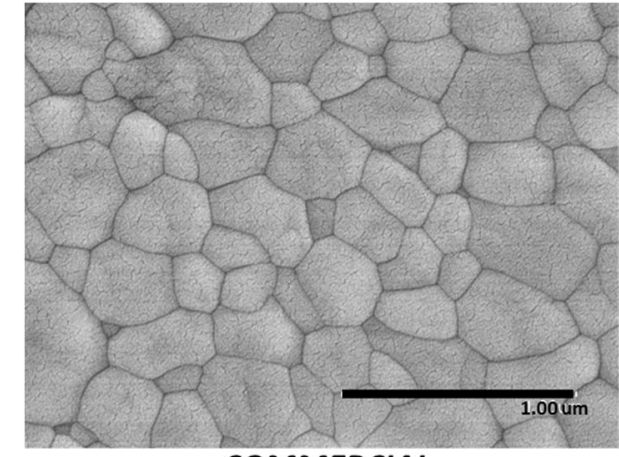

COMMERCIAL

$\mathrm{MW}, 1300^{\circ} \mathrm{C}, 10 \mathrm{~min}$

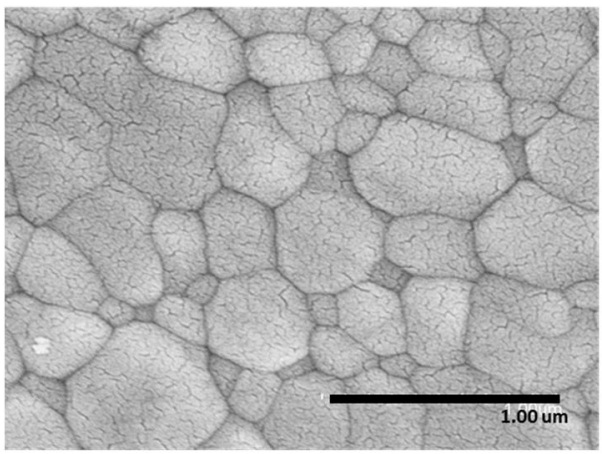

COMMERCIAL

$C S, 1400^{\circ} \mathrm{C}, 2 \mathrm{~h}$

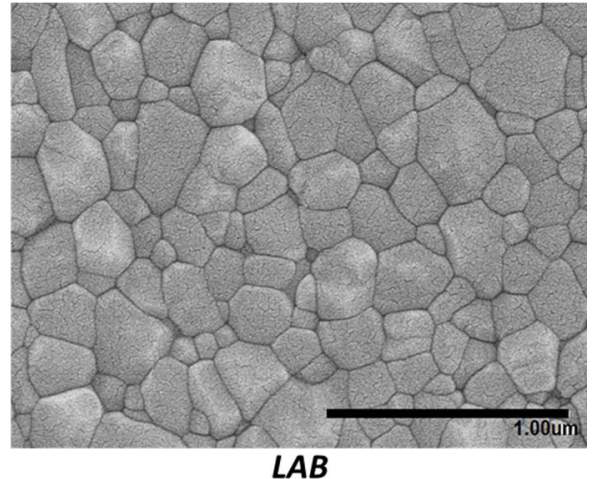

$\mathrm{MW}, 1300^{\circ} \mathrm{C}, 10 \mathrm{~min}$

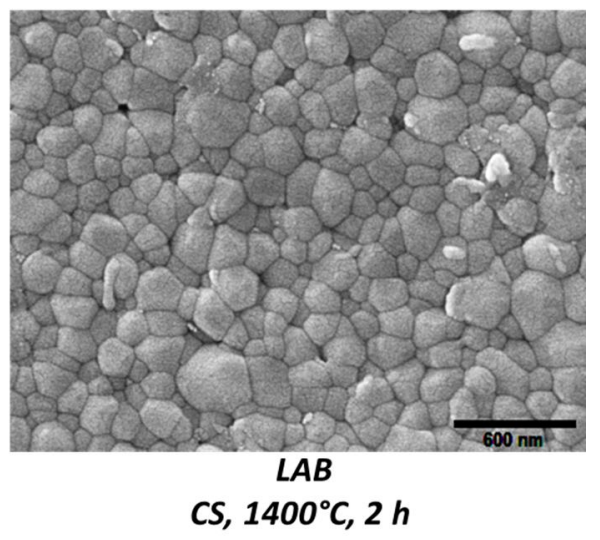

Figure 5. FE-SEM micrographs for COM M ERCIAL and LAB material under four different sintering conditions.

In $\mathrm{LAB}$ material, the resulting microstructure shows less variation in grain size when comparing both sintering methods. This is an important difference between COMMERCIAL and LAB material. The average grain size of MW-sintered samples of LAB is $174 \mathrm{~nm}$ for $1200{ }^{\circ} \mathrm{C}$ and 194 $\mathrm{nm}$ for $1300{ }^{\circ} \mathrm{C}$, while that of CS samples is $203 \mathrm{~nm}$ and $199 \mathrm{~nm}$ for 1300 and $1400{ }^{\circ} \mathrm{C}$, respectively. This means that the difference in grain size between $\mathrm{MW}$ and CS samples is less than $30 \mathrm{~nm}$. In this case, this behavior may be explained by the characteristics of the starting material because this material consists of particles with no aggregate and a previous rheological study resulting in an initial average particle size that is more uniform, so whether the material is sintered by MW or in a conventional furnace, the resulting microstructure is also more uniform with particle sizes that result in less variations after sintering. 


\section{Conclusions}

The results obtained in this work suggest that microwave sintering, in general, results in better mechanical properties in terms of hardness and fracture toughness than conventional sintering. In some cases, higher $H_{v}$ and $K_{I C}$ values have been determined at lower sintering temperatures with MW than those obtained for CS at higher sintering temperatures. It has also been established that the LAB material had the highest $H_{v}$ and $K_{I C}$ values, as well as that of relative density and the least variation in average particle size when sintered by different methods. This result is a consequence of the rheological study that has been carried out previously allowing for a more homogeneous starting powder free of aggregates, emphasizing the importance of the raw material. For COMMERCIAL, a smaller average particle size maybe obtained with microwave sintering.

\section{Acknowledgements}

The authors would like to thank the financial support received from Universidad Politécnica de Valencia under project SP20120677 and Ministerio de Economía y Competitividad (MINECO) and co-funded by ERDF (European Regional Development Funds) through the project (TEC201237532-C02-01). A. Borrell acknowledges the Spanish Ministry of Science and Innovation for a Juan de la Cierva contract (JCI-2011-10498). A. Presenda acknowledges the Generalitat Valenciana for his Santiago Grisolía program scholarship (REF. GRISOLÍA/2013/035). The authors would also like to acknowledge the SCSIE of the University of Valencia.

\section{References}

[1] C. Piconi, G. Maccauro, Zirconia as a Ceramic Biomaterial. Biomaterials, 20 (1999) 1-25.

[2] M. Guazzato, M. Albakry, S. Ringer, M. Swain, Strength, Fracture Toughness and Microstructure of a Selection of All-Ceramic Materials. Dental Materials, 20 (2004) 449-456.

[3] R. M. McMeeking, A. G. Evans, Mechanics of Transformation-Toughening in Brittle Materials. Journal of the American Ceramic Society, 65 (1982) 242-246.

[4] R. Benavente, Estudio de Materiales con Coeficiente de Dilatación Controlado Sinterizados por Técnicas No-Convencionales para Aplicaciones Espaciales, 2013, Master Thesis, Instituto de Tecnología de Materiales, Universidad Politécnica de Valencia.

[5] M. Oghbaei, O. Mirzaee, Microwave versus Conventional Sintering: A Review of Fundamentals, Advantages and Applications. Journal of Alloys and Compounds, 494 (2010) 175-189.

[6] K. Niihara, R. Morena, D. P. H. Hasselman, Evaluation of $\mathrm{K}_{\mathrm{IC}}$ of Brittle Solids by the Indentation Method with Low Crack-to-Indentation Ratios. Journal of Materials Science Letters, 1 (1982) 13-16.

[7] A. Borrell, M. D. Salvador, F. Peñaranda-Foix, J.M. Cátala-Civera, Microwave Sintering of Zirconia Materials: Mechanical and Microstructural Properties. International Journal of Applied Ceramic Technology, 10 (2013) 313-320.

[8] A. Borrell, M. D. Salvador, E. Rayón, F. Peñaranda-Foix, Improvement of Microstructural Properties of 3 Y-TZP Materials by Conventional and Non-Conventional Sintering Techniques. Ceramics International, 38 (2012) 39-43.

[9] J. R. Kelly, I. Denry, Stabilized Zirconia as a Structural Ceramic: An Overview. Dental Materials, 24 (2008) 289-298.

[10] S. Zinelis, A. Thomas, K. Syres, N. Silikas, G. Eliades, Surface Characterization of Zirconia Implants. Dental Materials, 26 (2010) 295-305. 